\title{
Drop dynamics and size distribution in a dense spray produced by a twin-fluid atomizer
}

\author{
Matheus Rover Barbieri ${ }^{\star 1}$, Alexander Zerwas², Jonathan Utzig ${ }^{3}$, Henry França Meier ${ }^{3}$, \\ Lydia Achelis ${ }^{1}$, Udo Fritsching ${ }^{3,4}$ \\ ${ }^{1}$ Particle and Process Engineering Department, University Bremen, Bremen, Germany \\ ${ }^{2}$ Chemical Engineering Department, University of São Paulo, São Paulo, Brazil \\ ${ }^{3}$ Chemical Engineering Department, University of Blumenau, Blumenau, Brazil \\ ${ }^{4}$ Leibniz Institut für Werkstofforientierte Technologien IWT, Bremen, Germany \\ ${ }^{*}$ Corresponding author email: m.barbieri@iwt.uni-bremen.de
}

\begin{abstract}
Motivated by industrial applications, the spray assessment of twin-fluid atomizers is paramount for improving their design and performance. Although several studies have addressed the spray characteristics, the coupled analysis of the droplet sizes and velocities at high flow rates is still not sufficiently understood. Therefore, the present study investigates the spray instabilities from a specific variance of a Y-jet atomizer correlated to droplet size and axial velocity distribution along the spray centerline. The atomizer was operated at Reynolds numbers in the order of $10^{4}$, resulting in different air-to-liquid mass ratios. For that, an experimental rig operated with air and water is available for spray analysis. Data obtained with a phase Doppler anemometer showed that the mass flow rate of both fluids is directly proportional to the velocities and inversely proportional to droplet diameters. The size-velocity correlations showed that closer to the spray, the smaller droplets had higher velocities than the bigger ones. As they flowed downstream the nozzle, the impingement between the droplets and their interaction with the surrounding air decelerated them and increased their size.
\end{abstract}

\section{Keywords}

Twin-fluid atomization. Droplet dynamics. Dense spray. Droplet size-velocity correlation.

\section{Introduction}

Chemical reactions and transfer phenomena are intensified by enabling a large interface surface between the fluids, which can be achieved by the atomization process. When dealing with high-viscous fluids and with high mass flow rates in industrial applications, gas-assisted atomizers have some advantages over pressure ones, mainly due to the less pressure required to disintegrate the liquid [11,14]. For this reason, they are widely employed in rocket engines, gas turbines, and in the oil industry, such as in fluid catalytic cracking (FCC) plants to transform crude oil into light fractions and more profitable products $[7,8]$.

Twin-fluid atomizers can be designed as external or internal mixing. The external mixing ones promote the first contact between the liquid jet and the gas stream outside the nozzle. In this context, Lampa and Fritsching (2016) [10] evaluated the simultaneous atomization and drying of Newtonian and viscoelastic fluids by hot gas, assessing the effects of gas temperature, gas pressure, and spray chamber design over droplet sizes and velocities. Heinlein and Fritsching (2006) [6] conducted a study of droplet clustering related to spray unsteadiness. The authors observed the formation of droplet clusters close to the spray boundaries, which increases with axial distances.

However, those in an internal-mixing configuration are of particular interest for the present study. They promote the first contact between the liquid jet and a high-speed gas stream in a 
chamber inside the atomizer [3,9]. Chin (1995) [3] describes some advantages of internalmixing twin-fluid atomizers over external mixing ones, such as a more intense contact between the gas and liquid phases inside the chamber, which results in finer atomization, and the possibility of operation with a broader range of liquids and operating conditions.

A widely used internal-mixing nozzle is the "Y-type" configuration. Its inner design consists of angled inlet ports for the fluids, which can be symmetrically distributed in the radial direction inside the nozzle in a ring-shaped format. Some studies proposed geometrical modifications to this type of nozzle aiming to improve it [2,5]. Typical are also internal-mixing atomizers with an asymmetrical radial distribution of inlet ports, as the nozzle analyzed in the present work, which consists of the impingement of two liquid jets, which are disintegrated by a central air stream.

Numerous parameters influence the atomization process. Among them, the Reynolds and the Weber numbers and the air-to-liquid ratio give information regarding the atomization regime and the quality of the spray. In this context, several studies addressed the dependence of the droplet size on the gas and liquid flow rates. Ferreira et al. (2009) [5] investigated different diameters of air and liquid ports for twin-fluid internal-mixing atomizers. By keeping a constant water mass flow rate $\left(950 \mathrm{~kg} \mathrm{~h}^{-1}\right)$, the authors observed a reduction of the droplet Sauter mean diameter as the air-to-liquid ratio increased from 0.01 to 0.20 . The same trend was observed by Barreras et al. (2006) [2], by comparing the performance of three twin-fluid nozzles based on the concept of the Y-jet nozzle using water and air. The authors also observed that the water mass flow rate had a lesser influence on the droplet sizes compared to the air flow rate. Chong and Hochgreb (2015) [4] evaluated a twin-fluid atomizer using air and diesel fuel at a gas mass flow rate in the range of 0.14 to $0.56 \mathrm{~g} / \mathrm{s}$ and a liquid mass flow rate of $0.14 \mathrm{~g} / \mathrm{s}$. Based on phase-doppler anemometry analysis, increasing the air mass flow rate resulted in smaller droplets and higher velocities in the spray centerline, which decelerated with the axial distance. Furthermore, the size and the velocity of droplets are inversely proportional, due to the momentum exchange between the liquid and the air.

Xia et al. (2017) [13] investigated a water-air impinging jets atomizer at different water and air flow rates, and different impinging angles. The droplet sizes firstly reduced with axial distance and then increased due to coalescence. The authors also observed that the axial droplet velocity had a more intense deceleration in regions closer to the nozzle and this reduction is attenuated after a certain axial distance from the impinging point.

The analysis of droplet size-velocity correlations can bring important information about the spatial development of the spray. By plotting the velocity for every measured size, characteristics of the spray such as the existence of breakup or coalescence effect can be estimated. However, only a few studies bring this discussion and usually at low mass flow rates of the liquid and the gas $[12,15]$.

With this background, the characterization of the spray is paramount for the atomizer design and performance. Although some studies have addressed the investigation of droplet dynamics, the coupled analysis between droplet diameter and local velocity at high mass flow rates has not yet been completely examined. Furthermore, the coupled investigation regarding the distribution of velocities for each droplet size along the spray centerline and varying the operating condition can explain important phenomena throughout the spray, such as the coalescence effect between droplets and their deceleration. Therefore, the present study consists of the investigation of spray characteristics from a specific variance of a $\mathrm{Y}$-jet atomizer, such as droplet size distribution, and mean axial velocity along different axial positions in the spray centerline. The atomizer was operated at liquid and gas Reynold numbers in the order of $10^{4}$. 


\section{Material and Methods}

A test bench was used by employing water and air as working fluids at room temperature of $20 \pm 2{ }^{\circ} \mathrm{C}$. The liquid was pumped to the nozzle by a centrifugal pump, passing by a flowmeter and a pressure sensor before reaching it. The compressed air was supplied by a central air supply, going through a flowmeter, a pressure, and a temperature sensor before being delivered to the nozzle. With this instrumentation, the mass flow rates of both fluids could be controlled. The spray, formed in a chamber at ambient pressure, had the liquid collected in a container to be repumped, composing a closed loop for the water.

Data regarding droplet sizes and velocities were obtained by a phase-Doppler anemometer (BSA 6000, Dantec Dynamics A/S, Tonsbakken, Denmark). On each measuring point, 20000 samples were used for computing the mean velocity and the Sauter mean diameter (SMD), defined in Eq. (1). The experiments were done in triplicate. An argon-ion laser is used to generate two green laser beams with a wavelength of $532 \mathrm{~nm}$. The focal length of the emitting optics is $750 \mathrm{~mm}$, while the focal length of the receiving optics is $1000 \mathrm{~mm}$. A detection angle of $30^{\circ}$ was used to acquire the first-order refracted light.

$$
S M D=\left[\frac{\sum_{j=1}^{n} n_{j} D_{j}^{3}}{\sum_{j=1}^{n} n_{j} D_{j}{ }^{2}}\right],
$$

where $n_{j}$ is the number of droplets in the discrete size class of diameter $D_{j}$.

The 10 measuring points lay on the central axis of the spray, according to Figure 1(a), where the geometry of the nozzle with important dimensions is also presented. Figure 1(b) shows a top view of the nozzle. The measurements range from $65 \mathrm{~mm}$ to $415 \mathrm{~mm}$ downstream of the nozzle in the axial direction (z-direction). Information about flow conditions right after the nozzle exit presents some experimental challenges due to the density of the spray and this information could be obtained by computational fluid dynamics. The region of the spray analyzed with the PDA had a burst validation higher than $90 \%$, however, the spherical validation ranged from $65 \%$ closer to the nozzle to $80 \%$ in the farthest regions.

25

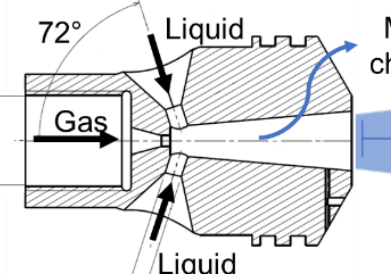

(a)

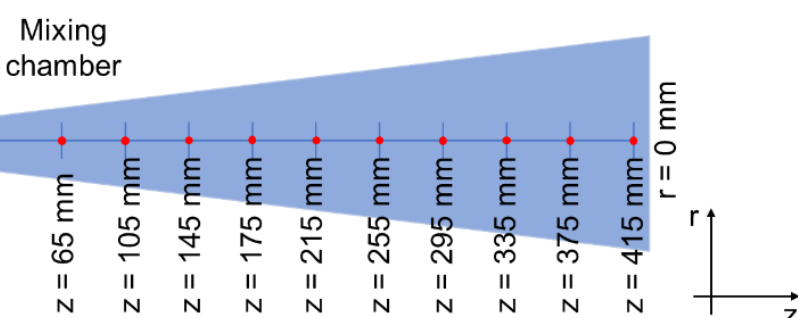

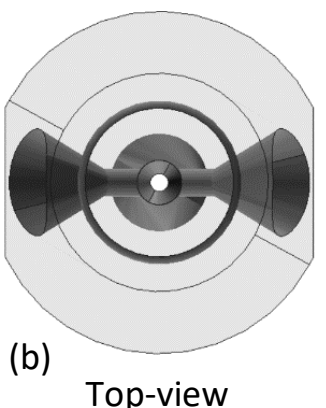

Figure 1. (a) Measuring points for the PDA along the spray centerline $(r=0 \mathrm{~mm})$ and important dimensions of the nozzle in millimeters. Note that in this figure the image has been rotated by $90^{\circ}$ counter-clockwise to save space, the atomization occurs vertically downwards. (b) top view of the nozzle.

Five operating conditions were evaluated in the present study, which comprise variations in the liquid and the gas mass flow rates. For clarification purposes, this study can be organized into two parts. The first one comprises a constant water mass flow rate of $2800 \mathrm{~kg} \mathrm{~h}^{-1}$, while the mass flow rate of air was varied between 46 and $69 \mathrm{~kg} \mathrm{~h}^{-1}$, according to the three most left sets of columns in Table 1. The second part consists of keeping the air mass flow rate constant at $69 \mathrm{~kg} \mathrm{~h}^{-1}$ and changing the water mass flow rate between $1400 \mathrm{~kg} \mathrm{~h}^{-1}$ and $2800 \mathrm{~kg} \mathrm{~h}^{-1}$, as presented in the most right sets of columns in Table 1. 
The air-to-liquid ratio (ALR), defined in Eq. (2) as the ratio between the mass flow rate of the air $\left(\dot{m}_{\text {air }}\right)$ and the liquid $\left(\dot{m}_{\text {water }}\right)$, ranged from 0.0164 to 0.0493 . Liquid and gas Reynolds numbers are also presented, which are calculated by Eq. (3). The gas Reynolds number was calculated in the section with a diameter of $25 \mathrm{~mm}$, while the liquid Reynolds number was calculated considering a diameter of $5.5 \mathrm{~mm}$ (see Figure 1(a)). In the considered region, the gas has a low Mach number, being reasonable to consider the gas flow incompressible in this region.

$$
\begin{aligned}
& A L R=\frac{\dot{m}_{\text {air }}}{\dot{m}_{\text {water }}}, \\
& R e_{i}=\frac{\rho_{i} U_{i} D_{i}}{\mu_{i}},
\end{aligned}
$$

where the subscript $i$ denotes the fluid (gas or liquid), $\rho_{i}$ is the fluid density, $U_{i}$ is the fluid velocity at the nozzle outlet, $D_{i}$ is the nozzle outlet diameter respective to each fluid and $\mu_{i}$ is the dynamic viscosity of the fluid.

\begin{tabular}{|c|c|c|c|c|c|c|c|c|c|c|}
\hline Properties & Water & Air & Water & Air & Water & Air & Water & Air & Water & Air \\
\hline $\begin{array}{l}\text { Mass flow } \\
\text { rate }\left(\mathrm{kg} \mathrm{h}^{-1}\right)\end{array}$ & 2800 & 46 & 2800 & 56 & 2800 & 69 & 2200 & 69 & 1400 & 69 \\
\hline $\begin{array}{l}\text { Inlet pressure } \\
\text { (bar) }\end{array}$ & 5.55 & 6.40 & 5.95 & 7.30 & 6.20 & 8.50 & 4.20 & 8.50 & 2.40 & 8.50 \\
\hline $\begin{array}{l}\text { Air-to-liquid } \\
\text { ratio (ALR) }\end{array}$ & \multicolumn{2}{|c|}{0.0164} & \multicolumn{2}{|c|}{0.0200} & \multicolumn{2}{|c|}{0.0246} & \multicolumn{2}{|c|}{0.0314} & \multicolumn{2}{|c|}{0.0493} \\
\hline $\begin{array}{c}\text { Reynolds } \\
\text { number }\left(\times 10^{3}\right)\end{array}$ & 89.14 & 35.54 & 89.14 & 47.27 & 89.14 & 53.31 & 70.03 & 53.31 & 44.57 & 53.31 \\
\hline
\end{tabular}

Table 1. Operating conditions considering variations in the gas and water mass flow rates.

\section{Results and Discussion}

The results and discussion section is divided into two subsections: firstly, the air mass flow rate effect over the droplet sizes and velocities is assessed. In the second part, the effect of the water mass flow rate is evaluated.

\section{Variation of the gas mass flow rate:}

Figure 2(a) shows the axial mean droplet velocity and Figure 2(b) presents the Sauter mean diameter for a constant water flow rate of $2800 \mathrm{~kg} \mathrm{~h}^{-1}$ at the center of the spray for the range of axial distance from 65 to $415 \mathrm{~mm}$ downstream the nozzle. The same colors represent the same air mass flow rate.

The main momentum transfer phenomena between the liquid and the surrounding air occur up to $215 \mathrm{~mm}$ downstream the nozzle, where the liquid suffers a stronger deceleration. Beyond this distance, the velocities are approximately constant until the end of the measuring section of the spray $(415 \mathrm{~mm})$. Considering the almost constant velocity plateau after $215 \mathrm{~mm}$, an increase of mass flow rate of air from $46 \mathrm{~kg} \mathrm{~h}^{-1}$ to $56 \mathrm{~kg} \mathrm{~h}^{-1}$ (an increase of $21.74 \%$ ) raised the velocity from about $46 \mathrm{~m} \mathrm{~s}^{-1}$ to $50 \mathrm{~m} \mathrm{~s}^{-1}$ (an increase of $8.70 \%$ ). An accretion from $56 \mathrm{~kg} \mathrm{~h}^{-1}$ to $69 \mathrm{~kg} \mathrm{~h}^{-1}$ of air (an increment of 23.21\%) increased the velocity from $50 \mathrm{~m} \mathrm{~s}^{-1}$ to $60 \mathrm{~m} \mathrm{~s}^{-1}$ on average (a gain of 20\%). Based on this, it can be observed that similar increases in the air mass flow rate resulted in more than double the velocity gain. 

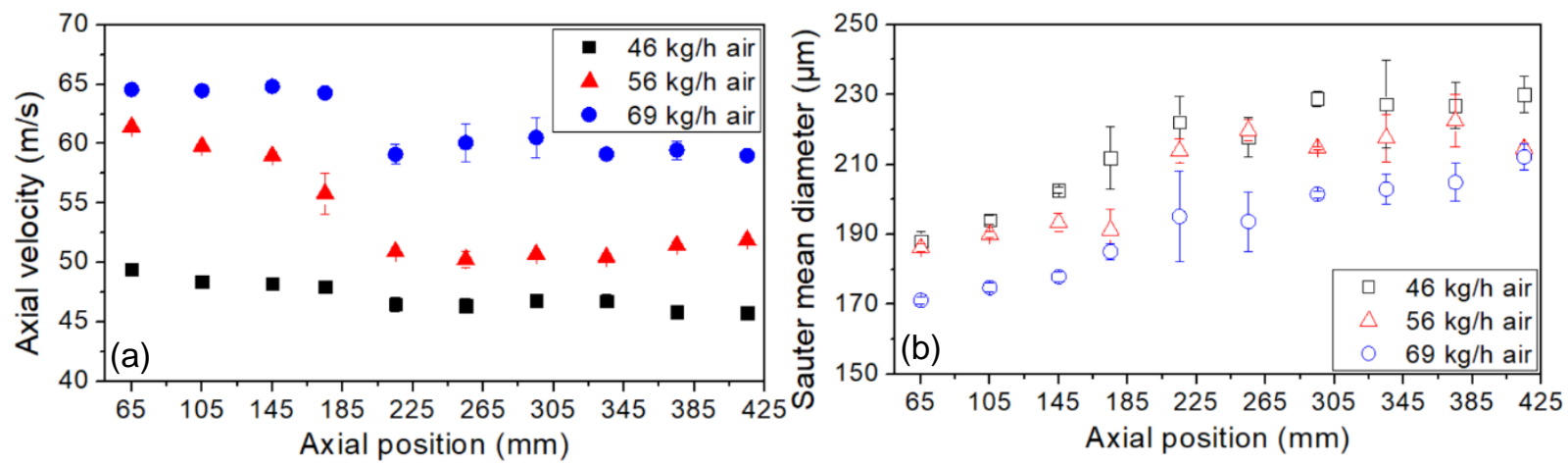

Figure 2. (a) Axial mean droplet velocity and (b) Sauter mean diameter for a constant water mass flow rate of $2800 \mathrm{~kg} \mathrm{~h}^{-1}$ and different air mass flow rates at different axial positions at the centerline of the spray.

A similar pattern to the velocity can be observed regarding the droplet size behavior in Figure 2(b). Although, in general, they do not stop growing, their size gain is attenuated after 215 $\mathrm{mm}$. The droplets' loss of momentum as they grow and flow downstream the nozzle outlet is related to the coalescence of droplets. This can be explained by looking at Figure 3, which shows the floating average profiles for the axial velocity versus the diameter for the measured droplets at each distance from the nozzle. Figure 3(a) is a sample graph showing the velocity versus the droplet diameter for all the measured droplets together with its respective floating average for an axial distance of $65 \mathrm{~mm}$ and $2800 \mathrm{~kg} \mathrm{~h}^{-1}$ of water and $46 \mathrm{~kg} \mathrm{~h}^{-1}$ of air.

The plots in Figure 3(b, c, and d) are used to quantitatively compare the operating conditions for a constant water mass flow rate and the air mass flow rates of 46,56 , and $69 \mathrm{~kg} \mathrm{~h}^{-1}$, respectively. Each profile color is a different axial distance in the spray centerline, according to the legend in Figure 3(b). While smaller droplets reach the maximum velocity in relatively less time, this process is slower for the large ones.

To some extent, the breakup process has finished, which means that the large droplets keep their velocity constant in the axial direction due to their relatively high momentum, while the smaller droplets lose momentum with the gas due to the interaction with the surrounding air, which agrees with the literature $[1,12]$.

In general, very small droplets have smaller velocities, which increase up to a size range of 50-100 $\mu \mathrm{m}$, reaching a maximum. From then on, they have their velocity reduced for bigger diameters. Closer to the spray outlet, that is, up to an axial distance of $215 \mathrm{~mm}$, the smaller droplets are faster than the bigger ones, explaining their impingement on the downstream and bigger ones, losing momentum, and flattening the velocity-diameter curve. After some distance, the velocities remain unchanged for the whole size range.

The increase of the air mass flow rate from 46 to $69 \mathrm{~kg} \mathrm{~h}^{-1}$ resulted in a general increase of velocity for all droplet sizes, while droplet diameters were reduced. The higher the gas mass flow rate, the higher the kinetic energy associated with the air flow, which causes a more vigorous contact between the phases inside the internal mixing chamber. Furthermore, the increment in the air mass flow rate from $46 \mathrm{~kg} \mathrm{~h}^{-1}$ to $56 \mathrm{~kg} \mathrm{~h}^{-1}$ amplified the difference between the velocity-diameter curves for each distance downstream the nozzle, while a further rise of the mass flow rate to $69 \mathrm{~kg} \mathrm{~h}^{-1}$ of air compacted again the curves for each axial position.

\section{Variation of the water mass flow rate:}

Figure 4(a) shows the mean droplet velocity and Figure 4(b) the Sauter mean diameter for a constant air mass flow rate and water mass flow rates of 1400,2200 , and $2800 \mathrm{~kg} \mathrm{~h}^{-1}$. Velocities and SMD for the same mass flow rates have the same marker colors. Especially for 
the lowest water mass flow rate of $1400 \mathrm{~kg} \mathrm{~h}^{-1}$, the velocity has a reduction trend for the whole axial position range. Similar behavior is noted for the other two liquid flow rates, but after some extent, notably after $215-255 \mathrm{~mm}$ downstream the nozzle, the reduction is softened.
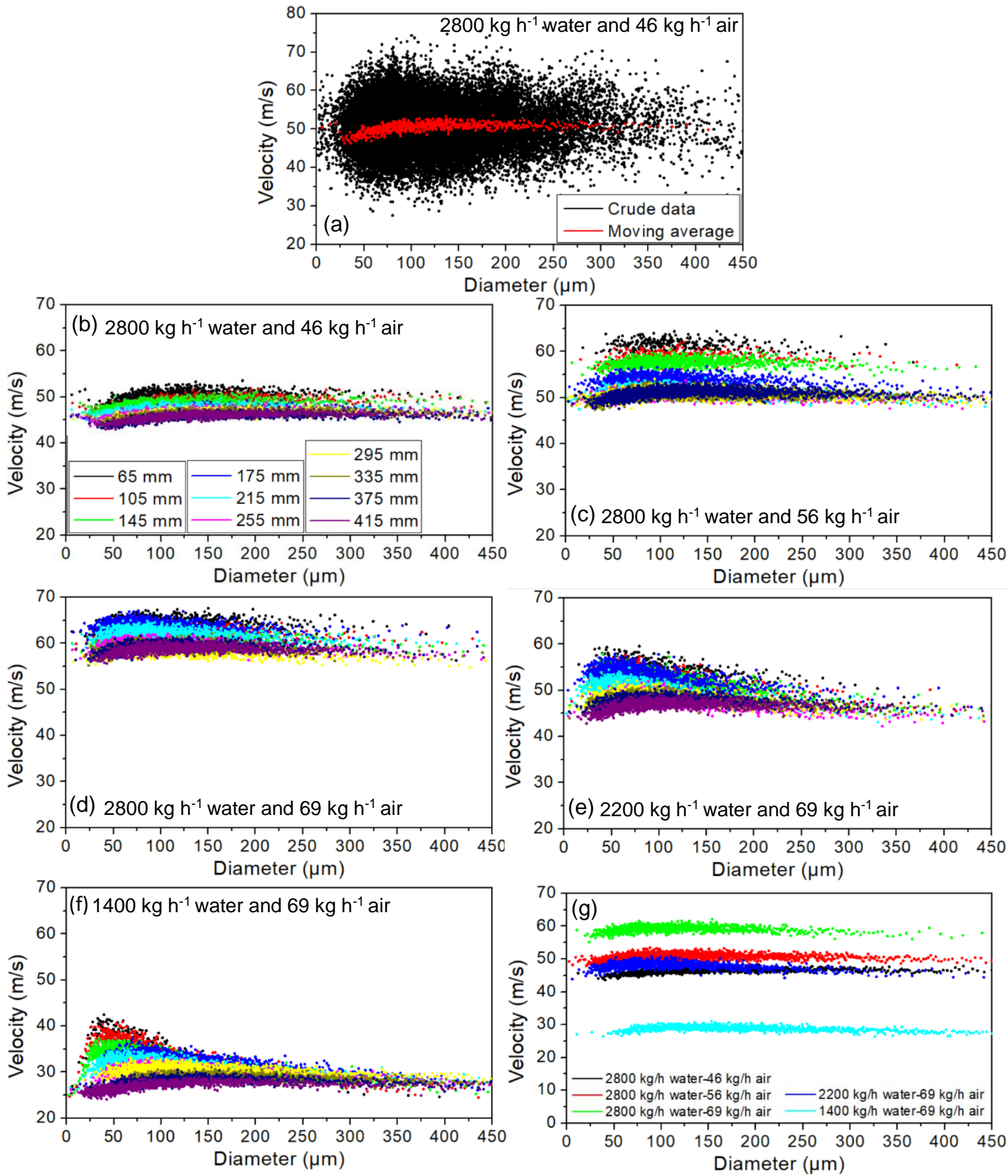

Figure 3. Correlation between droplet size and axial velocity together with a floating average profile for different axial distances at the spray centerline: (a) sample distribution at $65 \mathrm{~mm}$ for $2800 \mathrm{~kg} \mathrm{~h}^{-1}$ of water and $46 \mathrm{~kg} \mathrm{~h}^{-1}$ of air, (b) $2800 \mathrm{~kg} \mathrm{~h}^{-1}$ of water and $46 \mathrm{~kg} \mathrm{~h}^{-1}$ of air, (c) $2800 \mathrm{~kg} \mathrm{~h}^{-1}$ of water and $56 \mathrm{~kg} \mathrm{~h}^{-1}$ of air, (d) $2800 \mathrm{~kg} \mathrm{~h}^{-1}$ of water and $69 \mathrm{~kg} \mathrm{~h}^{-1}$ of air, (e) $2200 \mathrm{~kg} \mathrm{~h}^{-1}$ of water and $69 \mathrm{~kg} \mathrm{~h}^{-1}$ of air, (f) $1400 \mathrm{~kg} \mathrm{~h}^{-1}$ of water and $69 \mathrm{~kg} \mathrm{~h}^{-1}$ of air and $(\mathrm{g})$ different profiles for an axial distance of $335 \mathrm{~mm}$.

Alike the increase of the gas flow rate, the increase of the water mass flow rate induced higher velocities for the liquid droplets. However, distinct variations of the mean droplet velocity were 
observed depending on the operating condition. While the velocity difference between 46 and $56 \mathrm{~kg} \mathrm{~h}^{-1}$ increases from $40.37 \%$ to $74.76 \%$ at 65 and $415 \mathrm{~mm}$, respectively, the difference between 56 and $69 \mathrm{~kg} \mathrm{~h}^{-1}$ of air at the same positions is $17.75 \%$ and $24.41 \%$.
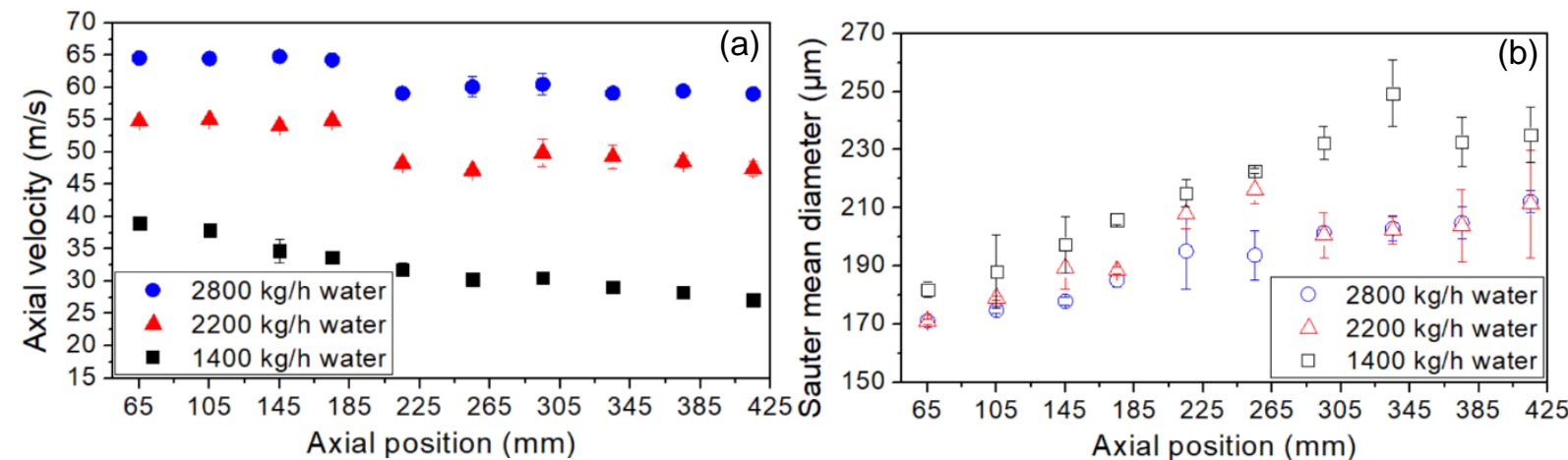

Figure 4. (a) Axial mean droplet velocity and (b) Sauter mean diameter for a constant air mass flow rate of $69 \mathrm{~kg}$ $\mathrm{h}^{-1}$ and various water mass flow rates at different axial positions at the centerline of the spray.

Higher velocities of the droplets due to the bigger water mass flow rates result in higher kinetic energy of the liquid, intensifying the contact between the phases. This, in turn, is associated with smaller droplets (see Figure 4(b)), with Sauter mean diameters inversely proportional to the liquid mass flow rate. In this case, the continuous increase of the droplet size with the axial distance is more evident than in the cases where the air mass flow rate was varied. This coalescence effect can be explained by the velocity-diameter plots in Figure 3(d-f). Higher velocities for the smaller droplets in regions close to the nozzle outlet favor the collision of the small droplets to the big ones. As the impingement occurs, the droplets lose momentum and have approximately the same velocity as they flow downstream, forming a stable region.

In general, the change in the water mass flow rate had a more significant impact on the droplet sizes and velocities than the change in the air mass flow rate. Such behavior can also be observed in Figure 3(g), which shows the velocity-diameter profiles for the five operating conditions at $335 \mathrm{~mm}$ downstream of the nozzle outlet. The three velocity-diameter profiles for constant water flow rate and changing the air mass flow rate are closer to each other, highlighting the small differences between the profiles for $46 \mathrm{~kg} \mathrm{~h}^{-1}$ and $56 \mathrm{~kg} \mathrm{~h}^{-1}$ of air, which notably raise for $69 \mathrm{~kg} \mathrm{~h}^{-1}$ of air. Conversely, when keeping a constant air mass flow rate, the water flow rate is proportional to the velocities of all droplet diameters, with slightly bigger velocities for smaller diameters, which reduce as the droplet size increase.

\section{Conclusions}

An air-assisted twin-fluid atomizer was investigated using the phase-Doppler anemometry technique. Measurements of droplet size and axial velocity were made for different axial distances from the nozzle outlet in the spray centerline on various operating conditions.

The investigation of the droplet size evolution showed an increasing trend in the axial direction. The growth in size was associated with the velocity-diameter plots, on which the droplets of smaller diameter, especially in axial positions closer to the nozzle, were faster than the bigger ones. This behavior resulted in an impingement of the upstream droplets over the downstream ones mainly at distances up to $215-255 \mathrm{~mm}$, which coalesced and lost momentum. From this distance on, the rate of velocity reduction was lower, resulting in almost constant values for further downstream distances, as an effect of droplets with similar size and velocity. This also impacted the droplet sizes, whose growth rate reduced after $215-255 \mathrm{~mm}$. 
The increase in both fluids' mass flow rates increased the flow velocity and reduced the SMD. Similar increases of the mass flow rate of the liquid $\left(1400 \mathrm{~kg} \mathrm{~h}^{-1}\right.$ to $2200 \mathrm{~kg} \mathrm{~h}^{-1}$ at a constant air flow rate of $69 \mathrm{~kg} / \mathrm{h})$ and the gas $\left(46 \mathrm{~kg} \mathrm{~h}^{-1}\right.$ to $69 \mathrm{~kg} \mathrm{~h}^{-1}$ at a constant water flow rate of 2800 $\mathrm{kg} / \mathrm{h}$ ) showed a stronger effect of the water flow rate on the velocity profiles and droplet sizes.

\section{Acknowledgments}

Funding for this project has been given with an international cooperation between the University of Bremen (GER) and the University of Blumenau (BRA) by means of a PETROBRAS project with cooperation agreement 5850.0107354.18.9. The support is gratefully acknowledged.

\section{Nomenclature}

$\begin{array}{llll}A L R & \text { air-to-liquid mass ratio }[-] & U_{i} & \left.\text { velocity of the fluid i [ } \mathrm{m} \mathrm{s}^{-1}\right] \\ D_{i} & \text { outlet diameter of the fluid } \mathrm{i}[\mathrm{m}] & W e & \text { Weber number }[-] \\ \dot{m}_{\text {air }} & \text { air mass flow rate }\left[\mathrm{kg} \mathrm{h}^{-1}\right] & \rho_{i} & \text { density of the fluid } \mathrm{i}\left[\mathrm{kg} \mathrm{m}^{-3}\right] \\ \dot{m}_{\text {water }} & \text { water mass flow rate }\left[\mathrm{kg} \mathrm{h}^{-1}\right] & \mu_{i} & \text { viscosity of the fluid i }\left[\mathrm{kg} \mathrm{m}^{-1} \mathrm{~s}^{-1}\right] \\ R e & \text { Reynolds number }[-] & \sigma & \text { surface tension }\left[\mathrm{N} \mathrm{m}^{-1}\right] \\ \text { SMD } & \text { Sauter mean diameter }[\mu \mathrm{m}] & & \end{array}$

\section{References}

[1] Aliabadi, A.A., Lim, K.W.J., Rogak, S.N., Green, S.I., 2011, Atomization and Sprays, 21 (12), pp. 1009-1031.

[2] Barreras, F., Lozano, A., Barroso, J., Lincheta, E., 2006, Atomization and Sprays, 16 (2), pp. 127-145.

[3] Chin, J.S., 1995, International Journal of Turbo Jet Engines, 12, pp. 119-127.

[4] Chong, C.T., Hochgreb, S., 2015, Atomization and Sprays, 25, pp. 657-673.

[5] Ferreira, G., García, J.A., Barreras, F., Lozano, A., Lincheta, E., 2009, Fuel Processing Technology, 90 (2), pp. 270-278.

[6] Heinlein, J. and Fritsching, U., 2006, Experiments in Fluids, 40, pp. 464-472.

[7] Jolodar, A.J., Akbarnejad, M.M., Taghizadeh, M., Marvast, M.A., 2005, Chemical Engineering Journal, 108 (1-2), pp. 109-115.

[8] Kumar, P., Sriganesh, G., 2019, International Journal of Petrochemical Science \& Engineering, 4 (3), pp. 109-115.

[9] Kushari, A., 2010, Particle and Particle Systems Characterization, 27 (1-2), pp. 32-41.

[10] Lampa, A. and Fritsching, U., 2016, "Hot gas atomization of complex liquids for powder production". In: Fritsching, U., 2016 "Process-Spray: Functional particles produced in spray processes", chap. 19. Springer.

[11] Lefebvre, A.H. and McDonell, V.G., 2017, "Atomization and Sprays". Second ed., Taylor \& Francis, CRC Press.

[12] Urbán, A., Zaremba, M., Malý, M. Józsa, V., Jedelský, J., 2017, International Journal of Multiphase Flow, 95, pp. 1-11.

[13] Xia, Y., Khezzar, L., Alshehhi, M., Hardalupas, Y., 2017, International Journal of Multiphase Flow, 94, pp. 31-43.

[14] Yarin, A.L., Roisman, I.V., Tropea, C., 2017, "Collision Phenomena in Liquids and Solids". First ed., Cambridge University Press.

[15] Zaremba, M., Weiß, L., Malý, M., Wensing, M., Jedelský, J., Jícha, M., 2017, International Journal of Multiphase Flow, 89, pp 277-289. 